\title{
Extrauterine Pregnancy: A Nine-Year Review of Incidence, Seasonality and Management at a Tertiary Hospital in Southern Ghana
}

\author{
Evans Kofi Agbeno1,2*, Anthony Amanfo Ofori'1,2, Joseph Osarfo ${ }^{3}$, Doughan Samuel ${ }^{2}$, \\ Joseph Amoah Adu ${ }^{1,2}$, Sebastien Ken-Amoah ${ }^{1,2}$, Wisdom Klutse Azanu ${ }^{4}$ \\ ${ }^{1}$ Department of Obstetrics and Gynaecology, School of Medical Sciences, University of Cape Coast, Cape Coast, Ghana \\ ${ }^{2}$ Department of Obstetrics and Gynaecology, Cape Coast Teaching Hospital, Cape Coast, Ghana \\ ${ }^{3}$ Ghana Health Service, Asante Mampong Municipal Hospital, Asante Mampong, Ghana \\ ${ }^{4}$ Department of Obstetrics and Gynaecology, School of Medicine, University of Health and Allied Sciences, Ho, Ghana \\ Email: *agbeno@yahoo.com
}

How to cite this paper: Agbeno, E.K., Ofori, A.A., Osarfo, J., Samuel, D., Adu, J.A., Ken-Amoah, S. and Azanu, W.K. (2020) Extrauterine Pregnancy: A Nine-Year Review of Incidence, Seasonality and Management at a Tertiary Hospital in Southern Ghana. Open Journal of Obstetrics and Gynecology, 10, 264-274.

https://doi.org/10.4236/ojog.2020.1020023

Received: January 6, 2020

Accepted: February 15, 2020

Published: February 18, 2020

Copyright $\odot 2020$ by author(s) and Scientific Research Publishing Inc. This work is licensed under the Creative Commons Attribution International License (CC BY 4.0).

http://creativecommons.org/licenses/by/4.0/ (c) (i) Open Access

\begin{abstract}
Introduction: Most cases of extrauterine pregnancies present in the ruptured state in low-resource settings and patients with haemodynamic instability risk mortality without swift intervention. An idea of when ectopic gestations are likely to present may be useful for logistic planning and facility readiness for case management. The study sought to assess the incidence of extrauterine gestation, mode of management and any link with seasonal and/or sociocultural events within the Cape Coast metropolis of Ghana over a 9-year review period. Methods: A retrospective review of all cases of extrauterine pregnancies managed at the Cape Coast Teaching Hospital (CCTH) from January 2010 to December 2018 was conducted. Data on patient age, parity, month of presentation, site and laterality of ectopic gestation, number of abortions and deliveries were retrieved from hospital records and analysed. Yearly and monthly aggregated incidence of extrauterine pregnancies were computed. Result: A total of 480 ectopic pregnancies out of 26,850 total pregnancies were seen over the period, giving an overall occurence of 17.9/1000 pregnancies and almost all were managed surgically. Half of all the cases occurred in the 20 - 29 years age group while the extremes of age recorded the lowest. An average of about 53 cases per year was recorded for the period under review. The peak months of occurrence were October and November. About 83\% were ruptured with the ampulla region being the commonest site. Conclusion: The data suggests increased ectopic gestation occurrence in the Cape Coast metropolis about two months after the major traditional festivals and this may have implications for instituting mitigating measures, logistic management and facility preparedness for case management.
\end{abstract}




\section{Keywords}

Extrauterine Pregnancy, Seasonality, Incidence, Ghana, Management Options

\section{Introduction}

An estimated 295,000 maternal deaths occurred in 2017 with Sub-Saharan Africa accounting for approximately $66 \%$ of these deaths [1]. Obstetric haemorrhage has been cited as the leading cause of maternal mortality worldwide and accounts for $27.1 \%$ of such deaths [2]. In sub-Saharan Africa, obstetric haemorrhage accounted for $24.5 \%$ of maternal deaths [2]. Extrauterine gestation is a key contributor and accounts for approximately $7 \%$ of mortalities due to obstetric haemorrhage and $2 \%$ of maternal mortalities in low and middle income countries [3]. Most cases of extrauterine gestation are not picked up early prior to rupture in low resource countries [4] [5] [6] [7].

Extrauterine gestation is the occurrence of an embryo outside of the uterine cavity. The most common site is the tube, with $64.4 \%-86.4 \%$ occurring in the ampulla region [4] [6] [7] [8] but the ovaries, the cervix, broad ligament and the abdominal cavity have also been recorded [9] [10] [11] [12]. A few cases of heterotopic and bilateral tubal ectopic gestations have been documented [13] [14] [15].

Three management options for ectopic gestation are available-expectant, medical and surgical. There is a criterion for all the options. The surgical management is the commonest, especially in resource-constrained settings, and could be approached from an open laparotomy, culdotomy or laparoscopically. Intraoperatively, a salpingectomy (partial or total), salpingotomy or salpingostomy can be used to manage tubal ectopics. The main indication is when the patient presents in a ruptured state and or when they do not qualify for medical management.

The medical management is suitable for those who present in an unruptured state; gestational sac less than $3 \mathrm{~cm}$; no foetal heart beat; serum BhCG levels < $5000 \mathrm{mmol} / \mathrm{ml}$; no contraindication to the medicines used and when the patient consents and will not be lost to follow up. The medical approach has the main advantage of tubal preservation.

The incidence of ectopic pregnancy, presented per deliveries, world-wide ranges from 1.02\% - 3.9\% [4] [5] [7] [8] [16] [17] [18]. While some studies have linked the occurrence of ectopic pregnancies to either climatic or sociocultural seasons [19] [20], others found no such associations [21] [22]. The knowledge of seasonal patterns in the occurrence of ectopic gestation enables facilities to heighten their diagnostic suspicions and put themselves in readiness for case management in terms of logistics planning and human resource availability. This is deemed especially useful in resource-constrained environments such as Ghana. Though some studies on ectopic pregnancies have been conducted in 
Ghana [7] [23] [24], none has examined seasonal variations in ectopic pregnancies and the possibility of a linkage between occurrence of ectopic pregnancies and sociocultural or festive events. A review by Baffoe et al. on ectopic pregnancies at the Korle-bu teaching hospital was limited to 3 years of data and did not examine seasonality [7]. The other published studies focused on risk factors associated with ectopic pregnancies [23] [24]. The current study presents a 9-year retrospective review of ectopic pregnancies with the aim of assessing the incidence, mode of management and any link with seasonal and/or sociocultural events within the Cape Coast metropolis of Ghana.

\section{Methods}

The Cape Coast Teaching Hospital (CCTH) is located in the Central region of Ghana and is the main referral facility for the Central and Western and some parts of Ashanti, Eastern and Greater Accra regions. It averages about 3000 deliveries annually. Obstetric haemorrhage in general accounts for up to a third of the maternal morbidities and mortalities (Biostatistics Unit, CCTH, 2018). The people of Cape Coast and its environs celebrate a number of socio-cultural events. Notable among them are Christmas, Easter (March/April) and the St. Valentine's Day but the most important cultural events are the Oguaa Fetu and the Bakatue festivals in August/September and June/July respectively.

The study participants were clients who had presented at CCTH and had had a history taken, physical examination and other relevant investigations done and been diagnosed with an ectopic pregnancy, ruptured or otherwise, and managed surgically or medically over a 9-year period from January 2010 to December 2018. Existing hospital data relating to ectopic pregnancies and intraoperative findings were retrieved from the admissions and discharge book at the delivery suite and patient registers at the operating theatre and recovery units of the obstetrics and gynaecology directorate. The variables for which data was extracted include patient age, parity, month of presentation at the hospital, site and laterality of the ectopic pregnancy. Two medical officers were trained to conduct the data extraction independently based on a template designed by the lead author who also validated $70 \%$ of the data against primary sources for quality control purposes.

In addition, the annual total number of abortions and deliveries from January 2010 to December 2018 were obtained from the biostatistics unit to help approximate the monthly and yearly total number of pregnancies over the period reviewed. These were used as the denominators to calculate incidence of ectopic gestation at the facility.

Data collected was double-entered into SPSS version 20, cleaned, checked for consistency and accuracy and analysed using same. Descriptive statistics such as frequencies and percentages were generated and displayed using tables and charts. Ethical clearance for the study was granted by the ethics committee of CCTH with the reference number CCTHERC/EC/2018/11. 


\section{Results}

Four hundred and eighty (480) ectopic pregnancies were recorded over the 9 -year period out of a total of 26,850 pregnancies collated. Over four-fifths of the ectopic gestations $(82.9 \%, 398 / 480)$ were ruptured at presentation while the rest $(17.1 \%, 82 / 480)$ were unruptured. The mean age (SD) of the study participants was 29 years (6.34) with a range of $14-49$ years. Majority of participants were in the age group $20-29$ and parity ranged from 0 to 8 (see Table 1). All the ectopic pregnancies, except one which was successfully managed medically, were managed surgically and in more than half of the cases (57.9\%, 278/480), the pregnancy was located in the ampulla region of the fallopian tube. The next most common site was the cornual area of the uterus which accounted for $13.3 \%$ (64/480). Table 2 shows the distribution of ectopic pregnancy sites recorded from the review while Figure 1 shows their laterality. Majority of cases occurred on the right side. There was no maternal death.

Table 3 shows the yearly prevalence of ectopic pregnancies (per 1000 pregnancies) seen at Cape Coast Teaching Hospital over the review period. The years 2010-2012 and 2018 recorded prevalence $\geq 20 / 1000$ pregnancies while the others recorded less with the least recorded in 2016.

Figure 2 shows the cumulative monthly numbers of ectopic pregnancies seen at $\mathrm{CCTH}$ over the period reviewed and was obtained by summing the numbers seen in particular months over 2010-2018. For instance, 43 reported for January is the sum of ectopic gestations presenting in all the months of January from 2010 to 2018.

With the cases aggregated into months, it was observed the least number or proportion was in June $(5.4 \%, 26 / 480)$ while November recorded the highest $(11.7 \%, 56 / 480)$. The second highest was in October $(11.3 \%, 54 / 480)$ with the months of May and September showing high points. Bringing the cumulative numbers of pregnancy per month into consideration (see Table 4), the aggregated monthly occurrence of ectopic pregnancies (per 1000 pregnancies) over the 9 year period showed values which were more than 20 from September to January with the highest peaks in November and October.

Table 1. Study participants' age and parity.

\begin{tabular}{ccc}
\hline & Frequency $(\mathrm{n})$ & Percentage $(\%)$ \\
\hline Age (years) $(\mathbf{N}=\mathbf{4 8 0})$ & 28 & 5.8 \\
$<20$ & 242 & 50.4 \\
$20-29$ & 182 & 37.9 \\
$30-39$ & 28 & 5.8 \\
$\geq 40$ & & \\
Parity (N = 480) & 132 & 27.5 \\
0 & 319 & 66.5 \\
$1-4$ & 29 & 6.0 \\
$\geq 5$ &
\end{tabular}

$\mathrm{N}$ is total number of study participants and $\mathrm{n}$ is the number in each category. 
Table 2. Sites of ectopic pregnancies recorded in a review of client records over 2010-2018 at Cape Coast Teaching Hospital.

\begin{tabular}{ccc}
\hline Site & Frequency & Percent (\%) \\
\hline Cornua & 64 & 13.3 \\
Isthmic & 31 & 6.5 \\
Ampullary & 278 & 57.9 \\
Fimbriae & 39 & 8.1 \\
Infundibulum & 4 & 0.8 \\
Abdominal & 18 & 3.8 \\
Ovarian & 10 & 2.1 \\
Cervical & 3 & 0.6 \\
Not specified & 33 & 6.9 \\
Total & $\mathbf{4 8 0}$ & $\mathbf{1 0 0 . 0}$ \\
\hline
\end{tabular}

Table 3. Annual Incidence of ectopic pregnancies in CCTH over 2010-2018.

\begin{tabular}{cccccc}
\hline Year & $\begin{array}{c}\text { Number of } \\
\text { ectopics (E) }\end{array}$ & $\begin{array}{c}\text { Number of } \\
\text { deliveries (D) }\end{array}$ & $\begin{array}{c}\text { Number of } \\
\text { abortions (A) }\end{array}$ & $\begin{array}{c}\text { Total pregnancies } \\
(\mathrm{E}+\mathrm{D}+\mathrm{A})\end{array}$ & $\begin{array}{c}{ }^{\circledR} \text { Incidence/1000 } \\
\text { pregnancies }\end{array}$ \\
\hline 2010 & 53 & 2308 & 241 & 2602 & 20.4 \\
2011 & 51 & 2106 & 238 & 2395 & 21.3 \\
2012 & 59 & 2435 & 251 & 2745 & 21.5 \\
2013 & 57 & 2628 & 280 & 2965 & 19.2 \\
2014 & 41 & 2734 & 288 & 3063 & 13.4 \\
2015 & 54 & 2843 & 164 & 3061 & 17.6 \\
2016 & 36 & 2916 & 173 & 3171 & 11.4 \\
2017 & 62 & 2980 & 155 & 3197 & 19.4 \\
2018 & 67 & 3160 & 121 & 3348 & 20.0 \\
\hline
\end{tabular}

${ }^{\oplus}$ Incidence of ectopic pregnancies per 1000 pregnancies was calculated as $\mathrm{E} /(\mathrm{E}+\mathrm{D}+\mathrm{A}) \times 1000$.

Table 4. Monthly cumulative numbers of ectopic pregnancies, number of pregnancies and prevalence of ectopic pregnancies/1000 pregnancies at CCTH from 2010 to 2018.

\begin{tabular}{|c|c|c|c|c|c|}
\hline Month & $\begin{array}{l}{ }^{\mathrm{a} C} \text { Cumulative number of } \\
\text { ectopic pregnancies per } \\
\text { month }\end{array}$ & $\begin{array}{l}\text { Cumulative number of } \\
\text { abortions per month }\end{array}$ & $\begin{array}{l}\text { Cumulative number of } \\
\text { deliveries per month }\end{array}$ & $\begin{array}{l}{ }^{\mathrm{b}} \text { Cumulative number of } \\
\text { pregnancies per month }\end{array}$ & $\begin{array}{c}{ }^{\mathrm{c}} \text { Monthly incidence of } \\
\text { ectopic pregnancies } / 1000 \\
\text { pregnancies }\end{array}$ \\
\hline January & 43 & 177 & 1719 & 1939 & 22.2 \\
\hline February & 31 & 178 & 1668 & 1877 & 16.5 \\
\hline March & 37 & 199 & 2025 & 2261 & 16.4 \\
\hline April & 28 & 180 & 2213 & 2421 & 11.6 \\
\hline May & 44 & 115 & 2493 & 2652 & 16.6 \\
\hline June & 26 & 138 & 2321 & 2485 & 10.5 \\
\hline July & 40 & 137 & 2373 & 2550 & 15.7 \\
\hline
\end{tabular}




\section{Continued}

\begin{tabular}{cccccc}
\hline August & 34 & 146 & 1933 & 2113 & 16.1 \\
September & 46 & 152 & 2002 & 2200 & 20.9 \\
October & 54 & 147 & 2015 & 2216 & 24.4 \\
November & 56 & 180 & 1874 & 2110 & 26.5 \\
December & 41 & 170 & 1815 & 2026 & 20.2 \\
Total & 480 & 1919 & 24,451 & 26,850 & 17.9 \\
\hline
\end{tabular}

${ }^{a}$ as in Figure 2, this is the sum of the ectopics seen in the various specific months over the review period. bthis is the sum of number of ectopic pregnancies, number of abortions and number of deliveries in each specific month over the review period. Hence, 1939 recorded for January is the sum of the aforementioned variables in all the months of January from 2010 to 2018. cthis is calculated as (cumulative monthly ectopic pregnancies/cumulative monthly number of pregnancies) $\times 1000$.

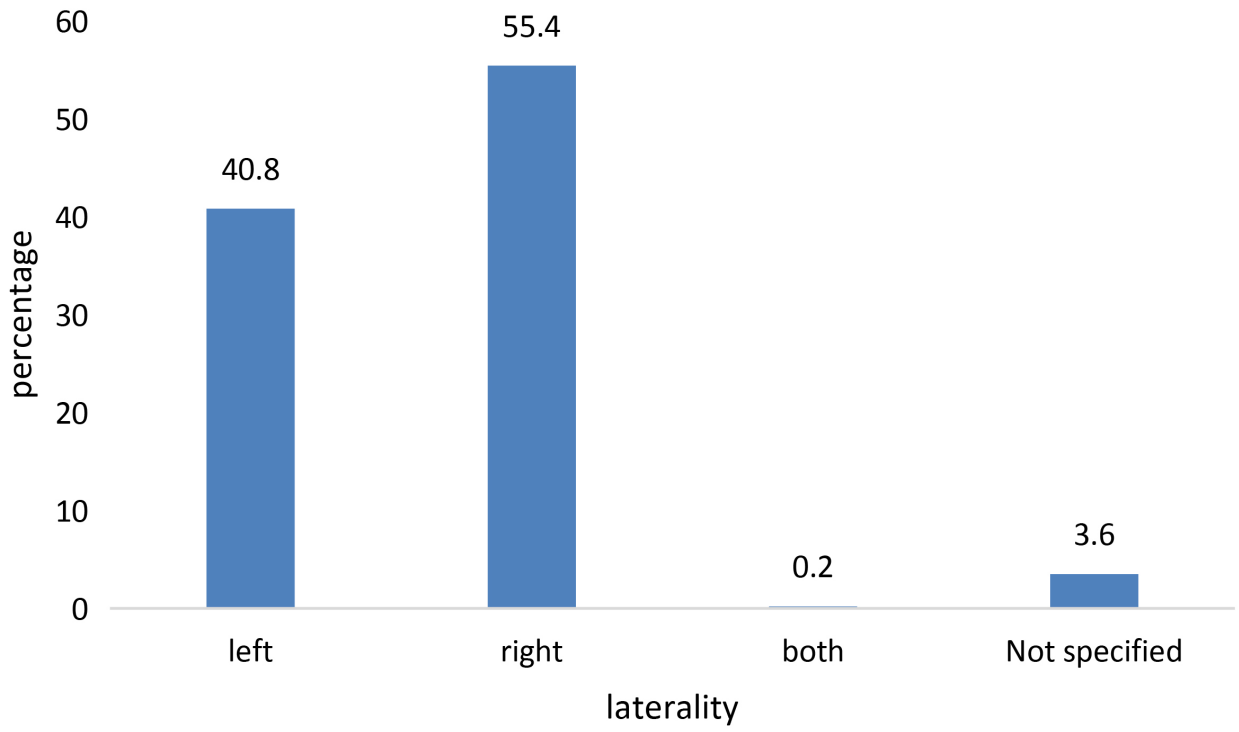

Figure 1. Laterality of ectopic gestations managed in CCTH over 2010-2018.

\section{9-year cummulative ectopic pregnancy cases per month}

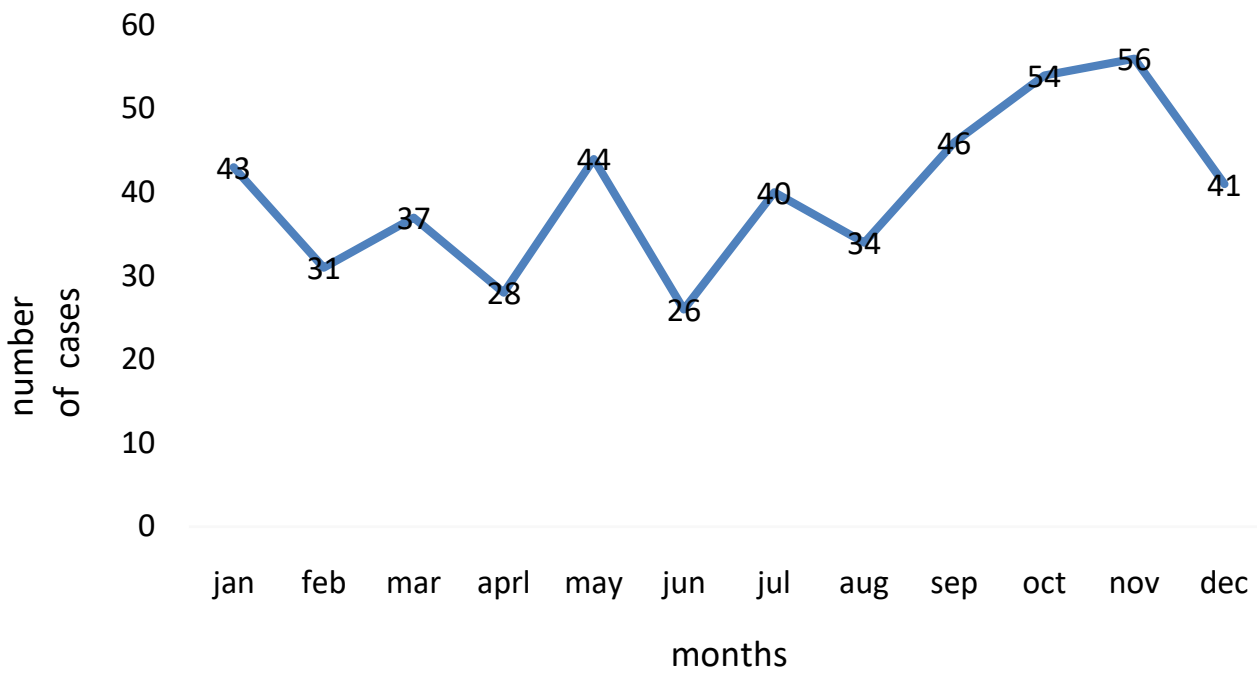

Figure 2. Cumulative monthly numbers of ectopic pregnancies seen at CCTH over 2010-2018. 


\section{Discussion}

A 9-year retrospective review of hospital data was done to assess the incidence, seasonality, and mode of management of extrauterine gestations at the Cape coast Teaching Hospital. The study found an overall extrauterine gestation incidence of 17.9/1000 pregnancies with the highest points occurring over the months of September to January. The commonest site of extrauterine gestation was in the ampulla region of the fallopian tubes with most of them being right-sided. Majority of them were ruptured at the time of presentation and surgery was employed as the mode of management in almost all the cases.

The incidence of $1.8 \%$ in this study is within the range of $1 \%-3.9 \%$ that has been reported from Ghana and the West Africa Sub-region [4] [7] [8] [16]. Similar rates have been reported from other parts of the world [17].

The highest occurence of extrauterine gestation was observed from September through to January with the highest incidence in November. There are 2 sociocultural events around the Cape Coast Metropolitan area that are associated with lots of festive activities and merry making. The first is the Bakatue festival of the Elmina people held every July. The second is the Oguaa Fetu festival that is celebrated in August/September every year. These festivals are typically characterised by a significant influx of people who hail from the area but live and work in other parts of the country, people without any ancestral links to the area but who come to partake in the merry-making activities and also increase in alcohol sales and consumption. We posit from observations made over time that a lot of unprotected sexual activity and excessive alcohol use among the youth occur during these festivals and is linked to a rise in early pregnancy complications including ectopic gestations two to three months later. Seasonal variation in the incidence of ectopic pregnancy is expected to differ from one geographic location to the other. Whiles some studies have reported seasonal variation in the incidence of ectopic pregnancy [19] [20], others did not find any such variation [21] [22].

The right sided dominance of ectopic pregnancy found in this study has also been reported by Wei Xia et al. and Islam et al. [6] [25]. This may results from the fact that ovulation occurs more frequently on the right side than the left as reported by Fukuda et al. [26].

Majority of patients in this study had their ectopic located in the ampulla region of the tube as noted in other studies [4] [6] [7] [8]. In addition, at least eight out of ten participants in the review presented in the ruptured state, a finding that has been reported by many authors in developing countries [4] [5] [6] [7]. This is probably because many women in the sub-region initiate antenatal care late, either out of financial constraints, ignorance or a socially-constructed fear of enemies harming their pregnancies spiritually [27] [28] making diagnosis of ectopic pregnancies prior to rupture virtually impossible. Even in situations where antenatal care is sought at an early gestation, ultrasonography is not widely available to make an early diagnosis of ectopic pregnancy. This is espe- 
cially the case in most rural and peri-urban areas.

Laparotomy was employed in the management of majority of the cases and this is consistent with findings from many studies in developing countries [4] [5] [8] [16]. The fact that many women presented in the ruptured state explains why laparotomy was employed in majority of the cases as medical management is contraindicated in ruptured ectopic gestations and laparoscopic services are not available at the site of the study. Though many women presented in the ruptured state, there was no maternal death from ectopic pregnancies in the period reviewed. While this may speak to the effectiveness of existing levels of preparedness, there will always be room for improvement to optimize preparedness for ectopic pregnancy case management at the study site especially with the months of September to January in mind.

The study is limited by the use of secondary data on ectopic pregnancy operative findings and represents the interpretation of the various cadres who conducted the operative procedures. Their reported findings cannot be independently verified now but the validity of the data is assured as these cadres were experienced medical officers and gynaecologists. Also, the number of ectopic pregnancies reported may have been higher if those from the Cape Coast Metropolitan Hospital and Ankaful General Hospital in the environs of CCTH had been added. However, there is confidence in the study findings as CCTH is the major centre in the area and absorbs the vast majority of cases requiring surgical interventions. Another limitation stems from the fact that the site of ectopic gestation was not specified in 33 out of the 480 cases reviewed. While this may underlie under-reporting in the frequencies of ectopic sites, it does not undermine the study's internal validity as the common sites observed resonate with previous studies. Lastly, though the study did not report on significance of differences in monthly counts or prevalence of ectopic gestations, the results remain relevant as it brings to fore a potential seasonality element in the occurrence of ectopic pregnancies in Cape Coast and its environs.

\section{Conclusion}

In conclusion, most cases of ruptured ectopic gestations were seen at the Cape Coast Teaching Hospital between the months of September and January and especially in October/November and it appeared to be a fall out from the festivals held in the area in the preceding $2-3$ months. This finding potentially presents a window period where limited resources may be mobilized for improved case preparedness in anticipation of increased numbers of women seeking care for ectopic pregnancies. Additionally, there should be targeted condom distribution at these festivals in addition to education on abstinence to help reduce the incidence of ectopic pregnancies, unwanted pregnancies and sexually transmitted infections. Education on emergency contraception as part of these festivals may also be considered. Furthermore, close to 1 in 5 ectopic pregnancies presented as unruptured but they were still managed surgically. Further research is required 
to find out why medical management is less preferred in the local setting and also whether the seasonal variation noted also holds for induced abortions in the same setting.

\section{Acknowledgements}

We wish to acknowledge all the clients whose hospital data inputs were used in this work. We are also grateful to the staff of the biostatistics unit of CCTH for their efforts in retrieving both old and recent registers from which data was retrieved.

\section{Source of Funding}

None Declared.

\section{Conflicts of Interest}

The authors declare no conflicts of interest regarding the publication of this paper.

\section{References}

[1] WHO (2019) Trends in Maternal Mortality 2000 to 2017: Estimates by WHO, UNICEF, UNFPA, World Bank Group and the United Nations Population Division.

[2] Say, L., Chou, D., Gemmill, A., Tunçalp, Ö., Moller, A.-B., Daniels, J., et al. (2014) Global Causes of Maternal Death: A WHO Systematic Analysis. The Lancet Global Health, 2, e323-e333. https://doi.org/10.1016/S2214-109X(14)70227-X

[3] Bailey, P.E., Andualem, W., Brun, M., Freedman, L., Gbangbade, S., Kante, M., et al. (2017) Institutional Maternal and Perinatal Deaths: A Review of 40 Low and Middle Income Countries. BMC Pregnancy and Childbirth, 17, Article No. 295. https://doi.org/10.1186/s12884-017-1479-1

[4] Cornelius, A.C., Onyegbule, A., Onyema, Uchenna, E.T. and Duke, O.A. (2014) A Five Year Review of Ectopic Pregnancy at Federal Medical Centre, Owerri, South East, Nigeria. Nigerian Journal of Medicine: Journal of the National Association of Resident Doctors of Nigeria, 23, 207-212.

[5] Deeba, F., Khan, B. and Khattak, S.N. (2012) Ectopic Pregnancy Management in Ayub Teaching Hospital Abbottabad: A Ten Year Survey. Journal of Ayub Medical College, Abbottabad: JAMC, 24, 78-81.

[6] Islam, A., Fawad, A., Shah, A.A., Jadoon, H., Sarwar, I. and Abbasi, A.U. (2017) Analysis of Two Years Cases of Ectopic Pregnancy. Journal of Ayub Medical College, Abbottabad: JAMC, 29, 65-67.

[7] Baffoe, S. and Nkyekyer, K. (1999) Ectopic Pregnancy in Korle Bu Teaching Hospital, Ghana: A Three-Year Review. Tropical Doctor, 29, 18-22. https://doi.org/10.1177/004947559902900108

[8] Sy, T., Diallo, Y., Toure, A., Diallo, F.B., Balde, A.A., Hyjazi, Y., et al. (2009) Management of Ectopic Pregnancy in Conakry, Guinea. Medecine Tropicale: Revue du Corps de Sante Colonial, 69, 565-568.

[9] Kirk, E., Condous, G., Haider, Z., Syed, A., Ojha, K. and Bourne, T. (2006) The Conservative Management of Cervical Ectopic Pregnancies. Ultrasound in Obstetrics and Gynecology. The Official Journal of the International Society of Ultra- 
sound in Obstetrics and Gynecology, 27, 430-437. https://doi.org/10.1002/uog.2693

[10] Shetty, S. (2014) A Clinical Study of Ectopic Pregnancies in Atertiary Care Hospital of Mangalore, India.

[11] Sharma, S., Pathak, N., Goraya, S. and Mohan, P. (2012) Broad Ligament Ectopic Pregnancy. Sri Lanka Journal of Obstetrics and Gynaecology, 33, 60-62. https://doi.org/10.4038/sljog.v33i2.4008

[12] Mouhajer, M., Obed, S. and Okpala, A.M. (2017) Cervical Ectopic Pregnancy in Resource Deprived Areas: A Rare and Difficult Diagnosis. Ghana Medical Journal, 51, 94-97.

[13] Liu, C., Jiang, H., Ni, F., Liu, Y., Zhang, W. and Feng, C. (2019) The Management of Heterotopic Pregnancy with Transvaginal Ultrasound-Guided Local Injection of Absolute Ethanol. Gynecology and Minimally Invasive Therapy, 8, 149-154. https://doi.org/10.4103/GMIT.GMIT 419

[14] Sugawara, N., Sato, R., Kato, M., Manome, T., Kimura, Y., Araki, Y., et al. (2017) Bilateral Tubal Pregnancies after a Single-Embryo Transfer. Reproductive Medicine and Biology, 16, 396-400. https://doi.org/10.1002/rmb2.12053

[15] Talbot, K., Simpson, R., Price, N. and Jackson, S. (2011) Heterotopic Pregnancy. Journal of Obstetrics and Gynaecology, 31, 7-12. https://doi.org/10.3109/01443615.2010.522749

[16] Akaba, G.O., Agida, T.E. and Onafowokan, O. (2012) Ectopic Pregnancy in Nigeria's Federal Capital Territory: A Six Year Review. Nigerian Journal of Medicine: Journal of the National Association of Resident Doctors of Nigeria, 21, 241-245.

[17] Al-Turki, H.A. (2015) A Review of 33 Years (1980-2013) of Data Indicating a Rise in Ectopic Pregnancy in Saudi Arabia. International Journal of Gynecology \& $O b$ stetrics, 128, 33-35. https://doi.org/10.1016/j.ijgo.2014.07.037

[18] Igwegbe, A., Eleje, G. and Okpala, B. (2013) An Appraisal of the Management of Ectopic Pregnancy in a Nigerian Tertiary Hospital. Annals of Medical and Health Sciences Research, 3, 166-170. https://doi.org/10.4103/2141-9248.113655

[19] Cagnacci, A., Landi, S. and Volpe, A. (1999) Rhythmic Variation in the Rate of Ectopic Pregnancy throughout the Year. American Journal of Obstetrics and Gynecology, 180, 1067-1071. https://doi.org/10.1016/S0002-9378(99)70596-X

[20] Goldenberg, M., Bider, D., Seidman, D.S., Lipitz, S., Mashiach, S. and Oelsner, G. (1993) Seasonal Patterns in Tubal Pregnancy. Gynecologic and Obstetric Investigation, 35, 149-151. https://doi.org/10.1159/000292687

[21] Eskandar, M., Archibong, E., Sadek, A. and Sobande, A. (2002) Ectopic Pregnancy and Seasonal Variation: A Retrospective Study from the South Western Region of Saudi Arabia. Bahrain Medical Bulletin, 24, 63-65.

[22] Romer, T., Schmidt, T., Negwer, U., Rosel, H.D. and Lober, R. (1994) Is There a Seasonal Incidence of Ectopic Pregnancy? A Retrospective Analysis. Zentralblatt fur Gynakologie, 116, 628-630.

[23] Asah-Opoku, K., Oppong, S.A., Ameme, D.K., Nuamah, M.A., Mumuni, K., Yeboah, A.O., et al. (2019) Risk Factors for Ectopic Pregnancy among Pregnant Women Attending a Tertiary Healthcare Facility in Accra, Ghana. International Journal of Gynecology \& Obstetrics, 147, 120-125. https://doi.org/10.1002/ijgo.12928

[24] Opoku, B.K., Nguah, S.B. and Azanu, W. (2013) Ectopic Pregnancy: Are Fair-Colored Women at Increased Risk? Gynecology, 1, 1.

https://doi.org/10.7243/2052-6210-1-1 
[25] Xia, W., Zhang, J., Zhang, D., Zhu, Q., Zhang, H., Huang, Z., et al. (2019) Left-Right Asymmetry of Tubal Pregnancy: A 12-Year Retrospective Hospital-Based Study. Journal of Minimally Invasive Gynecology, 26, 671-678. https://doi.org/10.1016/j.jmig.2018.07.010

[26] Fukuda, M., Fukuda, K., Andersen, C.Y. and Byskov, A.G. (2000) Right-Sided Ovulation Favours Pregnancy More than Left-Sided Ovulation. Human Reproduction, 15, 1921-1926. https://doi.org/10.1093/humrep/15.9.1921

[27] Ebeigbe, P.N. and Igberase, G.O. (2010) Reasons Given by Pregnant Women for Late Initiation of Antenatal Care in the Niger Delta, Nigeria. Ghana Medical Journal, 44, 47-51. https://doi.org/10.4314/gmj.v44i2.68883

[28] Kotoh, A.M. and Boah, M. (2019) "No Visible Signs of Pregnancy, No Sickness, No Antenatal Care": Initiation of Antenatal Care in a Rural District in Northern Ghana. BMC Public Health, 19, Article No. 1094.

https://doi.org/10.1186/s12889-019-7400-2 